\title{
O GOZO DA INSATISFAÇÃO NA RELAÇÃO SEXUAL
}

Silvia Lippi

Silvia Lippi

Universidade

Paris VII Diderot, Centro de Pesquisa em Psicanálise, Medicina e Sociedade, Paris, França.

RESUMO: O gozo feminino é considerado por Lacan como Outro em relação ao do homem. Em todo caso, este gozo é difícil de ser discernido, ainda mais que ele pode, como nos mostra a clínica, ser facilmente simulado por uma mulher. Mas por que uma mulher se coloca na posição de simular um orgasmo? O que está em jogo para ela nessa prática? Tentaremos mostrar que a simulação nãoéapenas sinônimo de frigidez. Não que ela não o possa ser, mas a simulação é também fonte de prazer para uma mulher e, de forma pardoxal, algo capaz de favorecer o "encontro" com o outro.

Palavras-chave: Gozo, orgasmo, simulação, frigidez, fantasma, sintoma, masturbação, falo, castração.

ABSTRACT: The enjoyment of the dissatisfaction in the sexual relationship. The feminine enjoyment is considered by Lacan, as "Other", compared to the enjoyment of the man. Anyway, it is difficult to enclose, especially since enjoyment can be, as shown by the clinic, easily simulated by a woman. But why does a woman put herself in the position of simulating the orgasm? What are the stakes of this practice? We would try to show that faking orgasm is not only a synonymous of frigidity. It could be, of course, but it is also a spring of pleasure for a woman and, paradoxically, an expedient capable of making possible the "gathering" with the other. Keywords: Enjoyment, orgasm, simulation, frigidity, fantasy, symptom, masturbation, phallus, castration.

DOI - http://dx.doi.org/10.1590/S1516-14982016002001 
“Eu não gozo. Mas com X era muito bom, o sexo era muito bom. Na verdade, eu não sei se gozava... não, acho que não. Eu não sei. Talvez. Em todo caso, era muito bom".

— sta mulher, assim como outras, não sabe se o $\operatorname{prazer}^{1}$ que ela sente no momento da relação sexual é um "verdadeiro" gozo (de acordo com suas palavras). Prazer, excitação, satisfação, submissão, gozo, amor: qual é a fronteira entre esses diferentes momentos para uma mulher durante a relação sexual?

Lacan insiste muito sobre o gozo feminino que só pode ser Outro, diferente do gozo do homem. Falar de gozo da mulher como um gozo Outro que não seja o fálico (isto é, para além do falo), ou como um êxtase, e compará-lo ao gozo místico, ${ }^{2}$ é, de fato, uma proposição inesperada, ou, pelo menos, impossível de ser verificada. Lacan refere-se a isso como uma suposição (LACAN, 1975, p.44): ele supõe um gozo que seria não-todo fálico. Como saber, entretanto, se o "gozo místico" é da mesma ordem do gozo sexual? Os escritos dos místicos não nos ajudam a determinar isso. E Lacan, em Ainda, nega-o de forma explícita: a mística e a sexualidade devem permanecer distintas aos nossos olhos. ${ }^{3}$ Ao mesmo tempo, ele se pergunta "[...] Por que não interpretar uma face do Outro, a face de Deus, como suportada pelo gozo feminino?" (LACAN, 1975, p.70).

O gozo místico, ligado ao encontro imaginário com Deus, seria "suportado", de acordo com a hipótese de Lacan, pelo gozo da mulher. Em particular, em relação ao gozo de Santa Tereza, Lacan afirma: "basta vocês irem à Roma e olhar a estátua de Benin para compreender, de imediato, que ela goza, isso não há dúvida. E de que ela goza? É claro que o testemunho essencial dos místicos é justamente dizer que eles o sentem, mas que eles não sabem nada sobre isso" (LACAN, 1975, p.70).

Aos olhos de Lacan, há um gozo que a mulher "não sabe nada sobre ele, a não ser que ela o sente" (LACAN, 1975, p.69). Mas para certas mulheres, a questão sobre o gozo é ainda mais enigmática: elas não têm certeza da natureza desse gozo a ponto de não mais saber se o sentem ou não.

\section{GOZO FÍsICO, GOZO PSÍQUICO}

O que dizer desta forma "inclassificável" de gozo — um gozo que não se sabe se é um gozo - , que não corresponde nem ao orgasmo (físico), nem a um gozo

\footnotetext{
${ }^{1}$ De agora em diante, vamos utilizar o termo "prazer" como sinônimo do termo "gozo", e não vamos nos referir ao uso que Freud faz desses termos em sua teoria do "princípio do prazer", como sendo o princípio regulador da excitação no psiquismo.

${ }^{2} \mathrm{O}$ gozo místico poderia ser outra forma de gozo fálico. Ele é um gozo que se realiza em nome de um pai idealizado, ainda ligado, então, de alguma forma, ao símbolo fálico.

3"Oque setentava no fim do século passado, nos tempos de Freud, oqueeles procuravam [...] era incluir a mística em casos de sexo. Se olharmos de perto, não é isso" (LACAN, 1975, p.71).
} 
suposto Outro que fálico, ou místico (um gozo que não se sabe nada, a não ser que se sente)?

Voltemosum instanteà SantaTereza. NãosepodeesquecerqueSanta Terezaé uma escultura feita por um artista que realiza, através de sua obra, suas fantasias de homem (sobre o gozo da santa, da mulher, etc.) ${ }^{4}$. Em todo caso, diante de uma mulher com a boca aberta, com os olhos fechados eem uma posição lasciva, pode-se sempre se perguntar se ela está gozando ou se está fazendo semblante. Para o homem que observa sua parceira quando ela goza, não é fácil saber se ela sente um êxtase sexual ou se ela está simulando o gozo.

Se na mulher a excitação sexual é manifesta (assim como no homem), o orgasmo feminino não mostra sinais tão "evidentes" quanto o masculino 5 . O gozo da mulher produz determinadas modificações corporais (contrações musculares, ejaculação...), mas essas modificações existem também durante a excitação sexual. Para o homem, entretanto, "excitação" e "orgasmo" são fenômenos fisicamente distintos (a não ser que ele esteja perturbado ao ponto de perder os sentidos, sua ereçãoe mesmo sua ejaculação são evidentes, seelegoza).

O gozo físico e o gozo psíquico ${ }^{6}$ devem ser distinguidos, ainda que eles possam acontecer ao mesmo tempo: "ejaculação" (descarga) e "gozo" não são a mesma coisa, e isto vale para os dois sexos. Por exemplo, um orgasmo não comporta forçosamente um gozo psíquico. ${ }^{7}$ Ou ainda, o gozo da masturbação não é da mesma ordem do gozo do coito, que inclui a presença do outro - a/o parceira/o que o desencadeia - e que é mais intenso se o outro participa ou goza.(Aquelequegoza sem se preocupar com ogozo do outro está mais próximo da masturbação do que da relação sexual.)

Para a mulher, não é o corpo que fala de seu gozo, pois seu corpo não mostra o que acontece no âmbito do gozo. Os homens quase sempre pensam que sabem (ou sentem) quando uma mulher atinge o orgasmo, mas isto permanece

\footnotetext{
${ }^{4}$ Bernin é um artista barroco e a arte do século XVII tende a desenvolver um sistema de expressões intenso, que provoca uma sobrecarga de paixão (ARGAN, 1968, p.318).

${ }^{5}$ Isso não quer dizer que para o homem o processo que conduz ao gozo seja simples e mecânico.

${ }^{6}$ O termo "gozo psíquico" é insuficiente, porém ele nos permite marcar a importância de um "encontro" no âmbito do fantasma para que um gozo possa se produzir. Alain Vanier lembra que, para Lacan, é preciso uma "consonância de inconscientes" para que alguma coisa aconteça no nível dos fantasmas entre um homem e uma mulher (Alain Vanier, Journées d'Automne d'Espace Analytique, L'insatisfaction, 21-22 novembre 2009, notas de conferência). Para Lacan, se nem todo homem tem vontade de todas as mulheres é "que nem todas estão em consonância com seu inconsciente" (LACAN, 1985, pp. 5-23). Lacan dirá também em 0 sinthoma: "Ionge do corpo, existe a possibilidade do que chamei, da última vez, de ressonância ou consonância" (LACAN, 2005).

${ }^{7}$ Muitos homens reclamam, com frequência, que o gozo com as mulheres não é satisfeito por completo - "módico", me diz um paciente — ainda que eles cheguem ao orgasmo (à descarga).
} 
na vertente da suposição, pois pode restar uma dúvida: trata-se de excitação ou de orgasmo? E como saber se ela goza ou faz semblante? A questão éainda mais difícil, pois a própria mulher pode confundir os dois, gozo e simulação.

A simulação tem relação com a frigidez feminina, mas não necessariamente. Tentaremos mostrar que a simulação é uma forma de gozo sintomática e alienante (esta será nossa primeira análise), mas também uma forma de abertura ao outro e ao seu gozo (é o que veremos em outro caso).

\section{SIMULAÇÃO E DESEJO DO OUTRO: O TODO-PODER DA MULHER}

Na simulação, é para dar prazer ao parceiro que a mulher finge o gozo: prazer do outro que — sozinho - engendra a satisfação (sintomática) do sujeito. Este prazer do prazer-do-outro está em contiguidade com a dor: dor erotizada, mas que a mulher costuma esconder para se apresentar ao seu parceiro como ocasião de prazer.

Uma mulher que simula o gozo aceita assumir um desejo que não é o seu; desejo que, entretanto, a atravessa, fazendo dela um objeto capaz de responderà exigência de gozo do outro. Um outro que se torna Outro: a mulher se submete a isso, ela se faz o instrumento do gozo do Outro, esquecendo o seu. Mas o sacrifício de seu próprio gozo é ainda um tipo de gozo — fracasso e gozo ao mesmo tempo: reconexão entre o sujeito e o Outro, gozo apático, vazio, uniforme, sem descontinuidade e sem ponto de parada.

Na relação sexual, o outro (o parceiro) deveria se opor ao Outro, sem se preocupar em visar a unidade fusional. O Outro não está alí para dar a ilusão de que a descontinuidade, a intermitência e a fratura entre os dois parceiros não existe mais. O outro como "terceiro", mas não no sentido de um "testemunho-espectador". O outro se redobra, ele é "objeto" e "meio" de gozo. No gozo da simulação, é como se faltasse o "terceiro", é um gozo próximo ao do autoerotismo. ${ }^{8}$

Simular esquecendo o próprio prazer, ou melhor, sacrificando-o ao outro/ Outro é uma forma de frigidez, frigidez que é sempre um gozo, um gozo solitário, pois o desejo do sujeito não é confortado pelo desejo do outro, mas somente pela sua demanda (de gozar). É o caso de uma mulher que me diz ter sempre simulado com seus parceiros, inclusive com seu marido: "eu nunca soube o que era

\footnotetext{
${ }^{8}$ Dizemos "autoerotismo" e não "masturbação". Autoerotismo, no sentido de "erotismo de si". Por precisão, dizemos que no autoerotismo a fantasia incestuosa ainda é dominante, a criança não chega a se separar da mãe, a se livrar de sua posição de objeto do desejo do Outro. A masturbação, em contrapartida, é uma verdadeira separação da mãe, separação que permite à criança se autossatisfazer. Ela se satisfaz em parte: a criança faz ao mesmo tempo a experiência do gozo (fálico) e da castração.
} 
um orgasmo antes de fazer amor com uma mulher. ${ }^{9}$ [...] Você sabe, os homens não entendem nada do corpo da mulher, isso não os interessa" ${ }^{10}$

Mas por que essa mulher simula? "Eu quero dar prazer a ele", ela me diz. "Eu não quero que eles fiquem decepcionados comigo. Sobretudo no começo eu pensava que o problema estava em mim e que eu não era boa". Ela continua: "Você sabe, com os homens, e em particular com meu marido, eu me sinto sempre inferior. Ele é meu ideal e eu devo dar o meu melhor, ou ao menos fazer semblante." Esta mulher sacrifica seu próprio gozo pelo ideal: ideal de homem, mas também de mulher que faz gozar.

Durante a simulação do gozo, a mulher imagina e representa, com as posturas de seu corpo e as expressões de seu rosto, um gozo sexual "perfeito". A "mulher que goza" (como Santa Tereza, para alguns psicanalistas) torna-se o ícone, o modelo, o ideal do gozo. E assim uma espécie de mulher ideal. Mulher-representação do gozo fora do limite: gozo magnífico, impecável, que não deve se confrontar com a castração. Figura feminina que se transforma em mulher toda-poderosa com um risco de confusão entre a mulher e a mãe. ${ }^{11}$

Uma mulher que escaparia à castração e que gozaria sem limites parece um sonho para certos homens. A mulher se superpõe à mãe neste gozo fora da castração: e o homem aceita de bom grado se fazer objeto, o instrumento suposto a ocasionar à mulher (ou à mãe?) um gozo Outro (suplementar, ilimitado, infinito).

Gozo perfeito $=$ mulher perfeita $=$ falo. Potência imaginária: a mulher se transforma em falo, via a simulação do gozo.

A simulação do gozo pode servir de técnica para fascinar o homem (efascinar o homem dá quase sempre prazer a uma mulher). Para os Romanos, a palavra phallus não existe: os romanos chamam fascinus o que os gregos chamam phallos (QUIGNARD, 1994). "Fascinar" quer dizer 'forçar aquele que olha a não mais separar o olhar' (como o homem que olha a mulher que finge gozar). Arrebatamento: é o homem que suporta o fascinus da mulher. Simulação como expressão do todo-poder (imaginário) da mulher, estranha forma de identificação com o falo. Excesso na forma, tendo em vista que ele não pode ter sentido: isolamento,

\footnotetext{
${ }^{9}$ Esta mulher nãoé nem homossexual, nem bissexual, ela teve apenas uma experiência com uma mulher em sua vida.

${ }^{10}$ Lacan, em Encore, falando de homens, diz "o sexo da mulher não (os) diz nada" (LACAN, op.cit., p.13). Lacan explica que o gozo físico do homem passa forçosamente pelo "intermediário do corpo", mais precisamente pelo órgão fálico, o que não quer dizer que o coito seja, para o homem — universalmente - um simples equivalente da masturbação. A imagem machista do homem que só pensa no seu pênis e no seu próprio gozo, negligenciando o da parceira, não corresponde sempre à realidade. Para muitos homens, a clínica mostra isso, o corpo e o gozo de suas parceiras contam bastante: o corpo e o gozo da mulher tornam-se elementos excitantes e gozosos para eles.

${ }^{11}$ Lacan, quando fala de Outro gozo (o gozo da mulher), não cai nesta confusão. Entretanto, como a relação entre o Outro gozo e o Gozo do Outro permanece enigmático na teoria lacaniana, vamos mantê-los separados.
} 
distância, alteridade da mulher. Negação do outro e de seu desejo, outro que existe apenas como espectador de um brilho vazio. O excesso é encenado para negar a castração.

A simulação do gozo é uma forma de potência imaginária, mas também de frigidez para a mulher. ${ }^{12}$ Frigidez que não é a negação do gozo, mas sintoma, isto é, uma forma de gozo substituto.

É um compromisso entre a possibilidade e a impossibilidade de gozar: um e outro, nem um nem outro (é a lógica "impossível" do inconsciente). A frigidez é uma espécie de gozo da insatisfação, um gozo sintomático que vem no lugar de um gozo sexual, difícil de obter, pois impõe a passagem pela castração e pelo outro. O gozo sexual está em antagonismo com o ideal (do outro, de si), e quando a questão do ideal não é resolvida, o gozo da insatisfação, ou seja, a frigidez, o substitui.

Escolher gozar não gozando permite à mulher não perder o controle durante o ato sexual. Se se quer continuar fálica, é melhor simular e gozar ser o objeto do gozo do outro (outro = Outro). O corpo torna-se representação da "coisa sexual" — o orgasmo —, impossível de suportar. Insuportável também para uma jovem mulher que não pode gozar com seu parceiro. Ela me diz também que não chega nunca ao final de suas atividades: é ela mesma quem faz a ligação entre sua vida profissional e sua frigidez na relação sexual. Não chegar até o fim quer dizer não arriscar: arriscar falhar ou arriscar conseguir?

A frigidez protege: medo de que um gozo que seja ou muito forte ou muito limitado (reenviando forçosamente à falta). Os dois ao mesmo tempo: o excessivo e o não suficiente, simultaneidade psíquica de duas moções inconciliáveis que mostram o impasse - extenuante, doloroso, incapaz de ser vivido - do sujeito sob o domínio da angústia de castração, angústia que se transforma em sintoma: a frigidez.

\section{SIMULAÇÃO E DESEJO DO OUTRO: O ENCONTRO}

A diferença entre simulação e gozo éàs vezes difícil de definir para quem o sente, vimos isso através da fala de muitas mulheres: ${ }^{13}$ entre prazer e dor, excitação e submissão, autenticidade e imaginação, o gozo escapa às palavras e mesmo às sensações. "Como eu posso compreender quando estou gozando de verdade?" me diz uma paciente, "o que é certo é que eu sinto prazer. Mas não é exatamente um alívio, eu não sei o que é. E ele (seu parceiro), me diz: 'você é magnífica quando goza'."

\footnotetext{
${ }^{12} \mathrm{~A}$ frigidez não é exclusivamente feminina, os homens também sofrem disso.

${ }^{13}$ Compreendemos tambéma modéstia ea prudência deFreud em relaçãoàs suas afirmações sobre o gozo feminino.
} 
Piera Aulagnier (1967), em "Remarques sur la féminité et ses avatars", analisa o caso de uma paciente que, após participar de uma conferência cujo título é 'O gozo: direito feminino', se pergunta se seu gozo é verdadeiro ou puro simulacro. "Acabei me perguntando [concluía a paciente], se meu gozo era um simulacro, um falso-semblante; mas o prazer que eu sinto é, porém, real. É como se viessem me dizer que o que existe de mais autêntico em mim é uma mentira, no entanto, essa mentira é o que sempre me pareceu verdadeiro por excelência." Piera Aulagnier acrescenta: "é nisso que o problema do gozo feminino beira sempre a dimensão do escândalo. [...] Para a mulher [...] a via do simulacro está sempre aberta, via que não deve ser considerada como simples sinônimo de impostura [...]" (AULAGNIER-SPAIRANI, 1967, p.59-65).

Vimos no parágrafo precedente que a simulação pode tornar-se uma escolha de conduta para uma mulher (por devoção ao homem) e uma forma de gozo autoerótico, capaz de desenvolver nela um sentimento de poder: simulando, uma mulher quer tomar a posição de mulher ideal capaz de fazer gozar o outro. O gozo que ela obtém disso é sintomático.

Piera Aulagnier fala, na passagem mencionada, de outra forma de simulação: uma simulação que, por seu caráter de "autenticidade" e de "verdade" — de acordo com as palavras de sua paciente - já é uma forma de gozo sexual, não necessariamente sintomático. A simulaçãonãoé por consequência uma mentira, uma mistificação do gozo: a simulação entra estruturalmente na constituição do gozo de certas mulheres, ela éaté mesmo uma condição (quase) indispensável.14

A simulação - expressão exagerada do prazer sentido — pode assim não ser antinômica de gozo, mas estar ligado a ele. O gozo da relação sexual não é um prazer "puro", isolado, destacado do parceiro e de seu próprio prazer; ele supõe a renúncia de um gozo singular, autoerótico, separado do outro. O coito não é uma experiência solitária como o êxtase ou a masturbação, ${ }^{15}$ mas um abandono de si que implica a presença do outro (de seu fantasma, de seu desejo, de seu prazer...). O sujeito larga mão disso - ele esquece o falo e o ideal — pois seu desejo é sustentado pelo parceiro (e vice-versa).

Muitas mulheres admitem que sempre simulam um pouco quando fazem amor. Simular: "eu te mostro que gosto do que você faz e estou com você, sinto prazer graças a você, pois é graças a você que obterei um gozo mais potente, que não posso obter sozinha".

Fazer o outro gozar faz parte do fantasma feminino. A simulação é um efeito deste fantasma. Mostrar ao parceiro um prazer que não está (ainda) presente, torna-se essencial a fim de desencadear nele o desejo, excitá-lo e fazê-lo gozar:

\footnotetext{
${ }^{14}$ Esta proposição não tem, é claro, valor universal.

${ }^{15}$ Os sujeitos, homens e mulheres, não são mônadas encapsulados em seus fantasmas. Um fantasma, como dissemos, éainda mais ativo seeleentra em consonância com outrofantasma.
} 
desejo, excitação e gozo que, a partir do outro, segundo a lógica do fantasma, retornarão ao sujeito.

A simulação não é sempre uma forma de alienação ao gozo do outro. O gozo é como uma bola, ele salta de um sujeito a outro: a simulação estimula gozos recíprocos.

Ao contrário da masturbação, a simulação no coito prova que uma mulher, através de seu fantasma, "vai" em direção ao outro; ela busca o encontro graças a seu próprio desejo de fazer o parceiro desejar e gozar. Desejo e gozo do outro que a farão ela mesma gozar: não se trata, na simulação, de um gozo orgástico.

É a partir deste mecanismo de "prazer invertido" que a simulação se transforma em gozo. No caso da simulação, simulacro do gozo, não é uma impostura, pois ela está para além do verdadeiro e do falso. "Simulacro", no sentido nietzschiano da palavra: o simulacro "aspira" à aparência, mas atrás da aparência não há substância, uma pretensa verdade última, "profunda". Tudo é dado de imediato, pois a verdade, de acordo com Nietzsche, não está em relação com a profundeza. O simulacro é então ao mesmo tempo verdadeiro e falso, ou o inverso, nem verdadeiro nem falso. Nem verdadeiro: pois a verdade é uma ilusão. Nem falso: pois a verdade existe, ela pode estar apenas na aparência do semblante (BARBERIS-LIPPI, 2009, p.170). Verdade da simulação, verdade da impossibilidade de compreendê-lo, este gozo da mulher, gozo que toma suas distâncias dasatisfação,satisfaçãoqueasimulaçãonegaeafirmaaomesmotempo.

Como dissemos mais acima, orgasmo físico e psíquico não estão necessariamente associados. O orgasmo psíquico é sempre difícil de discernir, pois os fatores que o produzem não estão, por força, ligados às reações corporais. $\mathrm{Na}$ simulação, ogozoéindependente do corpo, que intervém comofalso-semblante para sustentar o fantasma e o gozo do outro.

O que não quer dizer que não exista jamais "gozo do corpo" em uma muIher. Uma mulher me confia que para obter o orgasmo quando ela faz amor, deve se concentrar em uma parte precisa de seu próprio corpo, ou do corpo do outro, ${ }^{16}$ de forma quase fetichista. (Assinalamos que é sempre em relação ao outro - seu olhar, seus carinhos, etc. - que esta mulher se excita e goza com uma parte de seu corpo).

Isso nos interroga sobre a ideia que teria, de acordo com Lacan, um gozo para a mulher que "não passa pelo corpo", mas pelo "que resulta de uma exigência lógica na fala" (LACAN, 1975, p.15). Claro, o gozo não é estrangeiro à linguagem (tanto para o homem quanto para a mulher). As frases ditas no contexto sexual, assim como as palavras de amor são excitantes e podem fazer gozar, mas elas fazem gozar porque saem do contexto lógico do discurso. Como se elas não

\footnotetext{
${ }^{16}$ Parte que não corresponde necessariamente ao órgão sexual.
} 
fossem mais "linguagem": as frases sexuais e as palavras de amor ganham um valor corporal, pulsional, psíquico. Mas o que é um gozo "que resulta de uma exigência lógica na palavra?" Lacan pensa em um gozo que não dependa do prazer psíquico, um gozo que exclui o corpo por completo? Ou ele o considera como um gozo que deriva do fantasma?

Lacan fala também de um "Outro que se encarna [...] como ser sexuado" no gozo feminino. Outro que seria fora-do-corpo (então em relação com a linguagem). Este gozo fora-do-corpo, dominado pelo Outro da linguagem, de que fala Lacan, está mais próximo do gozo da simulação que do orgasmo feminino, que é, para todos os efeitos, como para o homem, "no-corpo".

\section{CONCLUSÃO: SIMULAÇÃO E CASTRAÇÃO}

Como diz a paciente de Piera Aulagnier, existe algo de verdadeiro na simulação. Verdade na dimensão "escandalosa" e inexplicada do gozo feminino, mas também verdade do fantasma, do desejo da relação sexual e do encontro com o outro nos gozos. A simulação - insatisfação e gozo, os dois ao mesmo tempo - mostra-se como falha da "verdadeira" fusão sexual, mas também como possibilidade de gozar a partir desta falha: a simulação é uma etapa que já faz gozar. Sem impedir uma continuação eventual, uma intensificação. Buscar o prazer sexual puro, que excluiria por completo toda forma de falso semblante, seria ainda da ordem do ideal e do impossível. O prazer vai sempre com o não-prazer ou o prazer não atingido até o fim: a simulação da mulher mostra que um gozo acabado e sem limites, para além da castração, é impossível, ou apenas imaginário.

Assim, a simulação não é apenas um sintoma, mas pode também se mostrar como uma forma de gozo que passa pela castração: resto de gozo sonhado e inacessível, tentativa falhada, barreira à fusão dos seres, signo de impotência do sujeito e da mulher. Barreira ao encontro absoluto, mas não ao gozo. $O$ simulacro do gozo já é um gozo: gozo da insatisfação, que carrega o signo da incompletude, mas não do impossível.

Recebido/Received: 3/5/2015. Aprovado/Accepted: 10/9/2015. 


\section{REFERÊNCIAS}

ARGAN, Giulio Carlo. (1968) Storia dell'arte italiana, v.3. Florence: Sansoni. AULAGNIER-SPAIRANI, P. (1967) "Remarques sur la féminité et ses avatars", in _. ; CLAVREUL J., PERRIER F., ROSOLATO G., VALABREGA J.-P. Le désir et la perversion. Paris: Seuil (coll. Essais).

BARBERIS, Orsola \& LIPPI, Silvia. (2009) Effraction et nom à I'adolescence: le tatouage, Cahiers de Psychologie Clinique n.33. Effractions d'adolescence. Bruxelles: De Boeck.

LACAN, Jacques. (1975) Le séminaire, livre XX, Encore. Paris: Seuil. (2005) Le séminaire, livre XXIII, Le sinthome. Paris: Seuil. . (1985) Conférence à Genève sur "Le symptôme", parue in Le Bloc-notes de la psychanalyse, n.5.

LIPPI, Silvia. (2008) Transgressions. Bataille, Lacan. Toulouse: Erès.

QUIGNARD, Pascal. (1994) Le sexe et l'effroi. Paris: Gallimard (coll. Folio).

Silvia Lippi

slippi@club-internet.fr

Traduzido do francês por Fabiana Campos Baptista/translater from french by Fabiana Campos Baptista

Centro Universitário de Belo Horizonte, Faculdade de Psicologia, Belo Horizonte/MG, Brasil.

fabibap77@hotmail.com 